\title{
Transverse Stress and Fatigue Effects in Y-Ba-Cu-O Coated IBAD Tapes*
}

\author{
J. W. Ekin, S. L. Bray, N. Cheggour, C. C. Clickner, S. R. Foltyn, P. N. Arendt, A. A. Polyanskii,
}

D. C. Larbalestier and C. N. McCowan

\begin{abstract}
Measurements of the effects of static and cyclic (fatigue) transverse stress on the critical current of Ya-Ba-Cu-O coated tapes made by ion-beam-assisted deposition (IBAD) are reported at $76 \mathrm{~K}$ in self magnetic field. Ya-Ba-Cu-O films ( $1 \mu \mathrm{m}$ thick) on Inconel substrates (100 $\mu \mathrm{m}$ thick) with IBAD buffer layers had critical-current densities $J_{c}$ exceeding $1 \mathrm{MA} / \mathrm{cm}^{2}$ and $n$ values of about 50 (where $n$ is an index of the sharpness of the superconductor-to-normal transition). Under static loads of $100 \mathrm{MPa}$, the degradation in $J_{c}$ was less than $5 \%$ ( $7 \%$ at $120 \mathrm{MPa})$. When subjected to cyclic loading, there was less than $2 \%$ additional degradation in $J_{c}$ after 2000 fatigue cycles. Microscopic examination of the samples indicates that this limited $J_{c}$ degradation may have arisen from longitudinal cracks forming near the edges of the sample after being subjected to these high transverse pressures. This fracture mode would indicate that longitudinal side support from high-yield substrates or epoxy impregnation of magnet structures may provide additional tolerance against degradation in $J_{c}$ from transverse stress.
\end{abstract}

Index Terms-Coated conductors, critical current, electromechanical, IBAD, mechanical, stress, transverse stress.

\section{INTRODUCTION}

$\mathrm{H}$ IGH critical current density $J_{c}$ in excess of $1 \mathrm{MA} / \mathrm{cm}^{2}$ in self field have been achieved recently at liquid-nitrogen temperature in flexible $\mathrm{Y}-\mathrm{Ba}-\mathrm{Cu}-\mathrm{O}$ (YBCO) coated conductors [1]-[6]. Little data are available, however, on the electromechanical properties of these conductors, which can strongly affect their ultimate usefulness in applications. Even superconductors that show high $J_{c}$ can have extremely different intrinsic stress tolerance, as shown earlier, for example, for Bi-2223 conductors [7]. Such electromechanical effects include degradation in $J_{c}$ arising from axial strain, bending strain, and transverse stress. For the coated conductors, there are only a few bending [4], [8], [9] and axial-strain [10] data available. In this paper, we present the first transverse stress data for $\mathrm{YBCO}$ coated conductors, measured for thick YBCO films on Ni-alloy substrates fabricated using ion-beam-assisted-deposition (IBAD) buffer

Manuscript received September 17,2000. This work was supported by the U.S. Dept. of Energy, Energy Efficiency Program and the U. S. Dept. of Energy, High Energy Physics Program.

J. W. Ekin, S. L. Bray, N. Cheggour, C. C. Clickner and C. N. McCowen are with the National Institute of Standards and Technology, Boulder, CO 80305 USA (e-mail: ekin@boulder.nist.gov, cheggour@boulder.nist.gov).

S. R. Foltyn and P. N. Arendt are with Los Alamos National Laboratory, Los Alamos, NM

A..A Polyanskii and D. C. Larbalestier are with University of Wisconsin, Madison WI.

${ }^{*}$ Contribution of NIST, not subject to copyright. layers. Both static and cyclic transverse stress effects on the critical current of these conductors were measured.

The effect of transverse stress on the critical current of superconductors is a critical design parameter for their application in magnets for high-energy physics accelerators, motors, generators, and superconducting magnetic energy storage. In such devices, the superconductor can be subjected to considerable transverse pressure, both from radial pressure developed in the winding of magnet coils and from the radial pressure of the Lorentz force when a magnet is energized. In the case of high-energy physics magnets, a benchmark transverse stress level is about $100 \mathrm{MPa}$.

\section{SAMPLE PREPARATION}

The tape samples were fabricated using the technique described in [11]. A $100 \mu \mathrm{m}$ thick Inconel ${ }^{\dagger} 625$ substrate was coated with a $\sim 0.9 \mu \mathrm{m}$ yttria-stabilized-zirconia (YSZ) IBAD layer, a $120 \mathrm{~nm}$ YSZ layer and a $\sim 30 \mathrm{~nm} \mathrm{Y}_{2} \mathrm{O}_{3}$ buffer layer. $\mathrm{A}$ YBCO superconductor layer, $0.9 \mu \mathrm{m}$ thick, was then deposited using pulsed laser deposition. Sample dimensions were $3 \mathrm{~mm}$ wide by $3 \mathrm{~cm}$ long.

Low contact resistivity was obtained by lightly cleaning the surface of the YBCO with an ion mill and then depositing a thick $(10 \mu \mathrm{m}) \mathrm{Ag}$ contact layer by thermal evaporation, which was later annealed in oxygen at $550{ }^{\circ} \mathrm{C}$. The $\mathrm{Ag}$ contact coating was $10 \mu \mathrm{m}$ thick in order to prevent the In solder from alloying completely through the Ag layer and forming an In-oxide barrier at the superconductor interface [12]. Notice that the YBCO layer is near the top surface of the tape, separated from the surface by only the soft $10 \mu \mathrm{m}$ Ag contact layer.

\section{EXPERIMENTAL TECHNIOUES}

In order to simulate the transverse stress environment these conductors will experience in service, testing was carried out in liquid nitrogen at $76 \mathrm{~K}$ by pressing the tape between two stainless-steel anvils, shown in Fig. 1, and measuring the

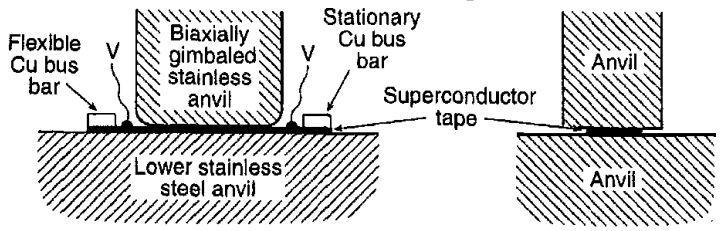

Side View

End View

Fig. 1. Transverse-stress test geometry. Transport current is in the plane of the paper for the side view, perpendicular to the paper for the end view. 


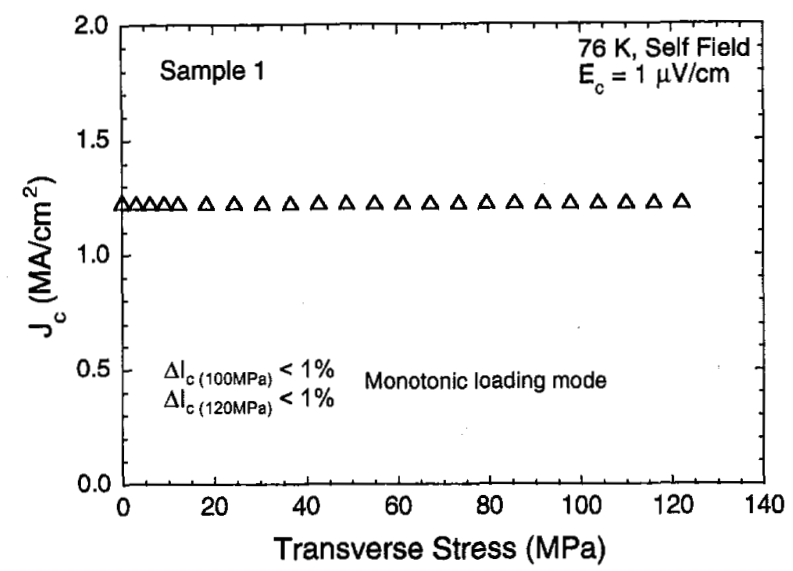

Fig. 2a. Effect of transverse stress on the critical-current density $J_{c}$ of a $\sim 1$ $\mu \mathrm{m}$ thick YBCO film deposited on a $100 \mu \mathrm{m}$ thick Inconel 625 substrate with IBAD buffer layers. Results were obtained using the monotonicloading mode (see text).

voltage vs. current characteristic of the test sample in self field while under load. Critical current was determined within about $\pm 2 \%$ using an electric-field criterion of $1 \mu \mathrm{V} / \mathrm{cm}$.

Uniform application of transverse stress was ensured by constructing the top anvil so it was biaxially gimbaled to conform precisely to the lower anvil surface. Stress concentrations were mitigated at the edges of the top anvil by making it wider than the tape width and flaring the edges, as shown in Fig. 1. Transverse stress was determined from the quotient of the applied load and the pressed area of the sample (equal to the product of the tape width and the length of sample under the upper anvil).

At each end of the sample, copper current-bus bars were soldered (without flux) onto the top thick $\mathrm{Ag}$ contact layer with eutectic In-3\% Ag solder $\left(T_{m e l l}=143^{\circ} \mathrm{C}\right)$, with a technique described in [12]. Solder flux is not needed to wet the $\mathrm{Ag}$ layer if the $\mathrm{Ag}$ is fresh and not tarnished; it was omitted to insure that the surfaces of the test sample and pressure anvils remain clean. One of the current bus bars is a high-conductivity copper strip designed to flex and provide axial-stress-free cooling of the sample (that is, it eliminates axial stress from differential thermal contraction between the sample and stainless-steel anvils) [13]. No transverse stress was applied during cooling so that the test sample was cooled in a completely stress-free manner.

Voltage taps were soldered with In-3\%Ag to the middle of the top surface of the tape sample, about $2 \mathrm{~mm}$ outside the pressing region. About 1 to $2 \mathrm{~mm}$ space was also allowed between the voltage tapes and the edge of the current contacts to eliminate current transfer voltages [14]

\section{TRANSVERSE STRESS RESULTS: INITIAL LOADING}

Two test modes were used for loading the conductors. In the monotonic laading mode, transverse stress was applied to Sample 1, a voltage vs. current $(V-I)$ characteristic measured, and then, without removing the load, the pressure was increased to a higher value and the $V-I$ characteristic

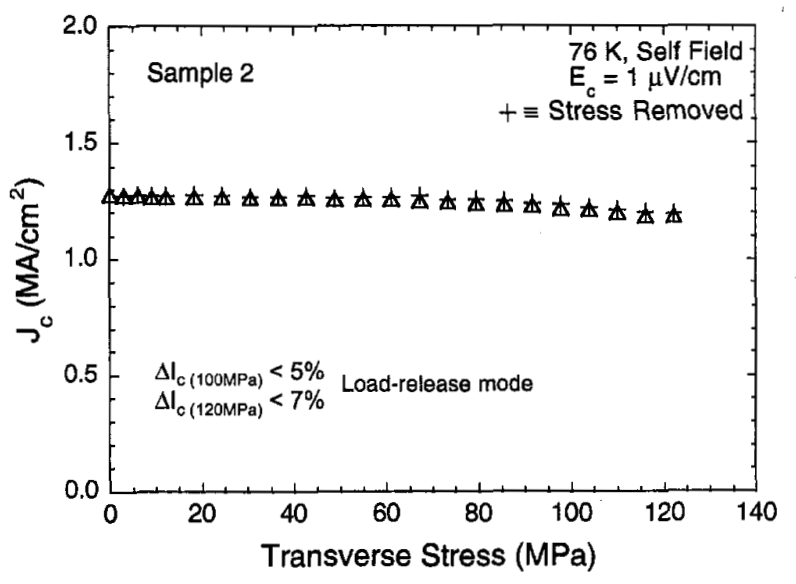

Fig. 2b. Same as Fig. 2a, except tested in the load-unload mode.

measured again. This procedure was repeated until pressures exceeding $100 \mathrm{MPa}$ were reached. We believe this is an optimistic measuring mode wherein the sample does not lose contact with the pressure anvils. The sample receives frictional support by being pressed against the stainless steel, providing additional strength against in-plane plastic strain.

The results of this test are shown in Fig. 2a, where the critical current is plotted as a function of transverse stress. Notice that the IBAD tape had a critical current density well over $1 \mathrm{MA} / \mathrm{cm}^{2}$. Also, the sample had a very sharp superconductor-to-normal transition characterized by an $n$ value of 47 (where $V \propto I^{m}$ ), indicating the sample to be of high quality and free of appreciable nonuniformities in the current distribution along the tape [15]. For this test mode, the critical-current degradation was less than $1 \%$ up to 120 $\mathrm{MPa}$, which is well beyond the design benchmark for accelerator magnets, for example.

In the second, load-unload test mode, transverse stress was applied to Sample 2, $J_{c}$ was measured (shown by a triangle in Fig, 2b), and the sample was then unloaded. $J_{c}$ was remeasured at zero load and the result indicated by a cross in Fig. $2 b$, which was plotted for comparison purposes at the same load as its corresponding loaded $-J_{c}$ value. The sample was then loaded to a higher stress and the load-unload procedure repeated. We believe this is a pessimistic, more conservative testing mode in which frictional support to the sample from the stainless-steel anvils is reduced, allowing inplain expansion of the tape between loading steps. Nevertheless, the degradation in this case was less than $5 \%$ at $100 \mathrm{MPa}$, increasing to $7 \%$ at $120 \mathrm{MPa}$.

Note that the $J_{c}$ on unloading did not recover to the initial $J_{c}$ value, indicating that the degradation in $J_{c}$ was irreversible.

\section{DISCUSSION}

The monotonic-loading test mode should be representative of a tightly wound magnet structure wherein the coated conductor is co-fabricated or co-wound with a high-yield structural layer that would press against the YBCO superconductor layer. The second, load-unload mode represents a case where the coated conductor loses the 


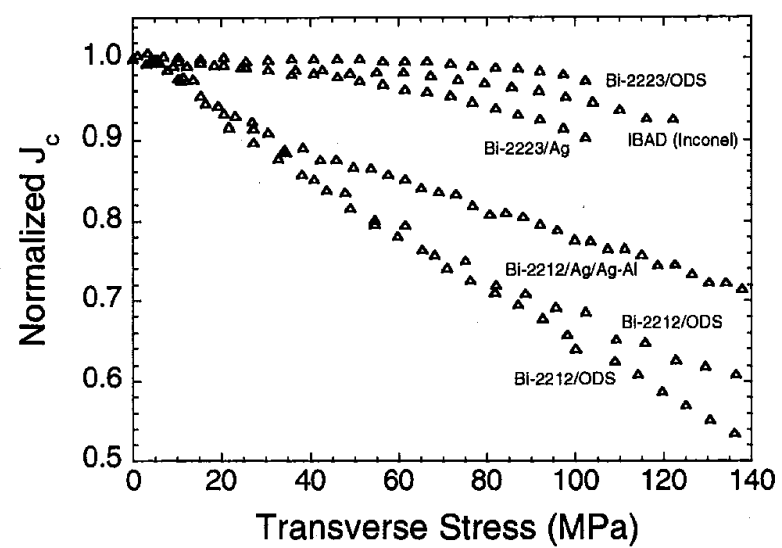

Fig. 3. Comparison of the effect of transverse stress on the $J_{c}$ of various high- $T_{c}$ tape conductors: IBAD, Bi-2223 [with $\mathrm{Ag}$ and oxide dispersion strengthened (ODS) Ag matrices], and Bi-2212 (with ODS Ag matrix, and double sheathed with $\mathrm{Ag}$ and $\mathrm{Ag}-\mathrm{Al}$ matrices). The results shown were obtained in the more severe load-unload testing mode.

frictional support of the pressure surface between each energizing of the magnet, and represents a worst case. Actual magnet performance is expected to be between these two situations. Since the envelope between the two sets of results for the IBAD coated conductors is narrow, we would expect the transverse stress tolerance for these IBAD tapes to be excellent, less than $5 \%$ at $100 \mathrm{MPa}$ in the worst case.

Fig. 3 compares these data with similar transverse-stress results obtained on several series of $\mathrm{Bi}-2223$ and $\mathrm{Bi} 2212$ tape conductors. Here, we compare the data for only the worstcase load-unload mode, to provide a lower limit on expected performance. The data fall into two distinct groupings. The IBAD and Bi-2223 results show high transverse stress tolerance, with less than $10 \%$ degradation at $100 \mathrm{MPa}$. The Bi-2212 performance was variable, with $J_{c}$ degradation between $20 \%$ and $35 \%$ at $100 \mathrm{MPa}$ transverse pressure. This is not to say that the Bi-2212 conductors cannot be successfully utilized at high transverse compressive loads in magnet applications, which could be accomplished, for example, by providing good structural side support [16]. The results, however, show the intrinsic stress tolerance of these different conductors, and in that vein, the IBAD coated conductors on Ni-alloy substrates look very robust. Note that Inconel has a relatively high yield stress compared with other substrate materials, which may account for their superior intrinsic stress tolerance.

\section{FATIGUe RESULTS}

Fig. 4 shows the effect of cyclic (fatigue) loading on the same conductors whose static test results are presented in Figs. 2a,b. Cyclic testing was performed after the samples had been subjected to static stress from the initial loading. Load was cycled between $122 \mathrm{MPa}$ and near zero at $0.33 \mathrm{~Hz}$, but never fully released $\left(J_{c}\right.$ was not measured at near zero load). As shown in Fig. 4, no further $J_{c}$ degradation occurred after an additional 2000 constant load cycles had been applied to Sample 1 (which showed less than $1 \%$ degradation in the initial monotonic loading). For Sample 2 (which

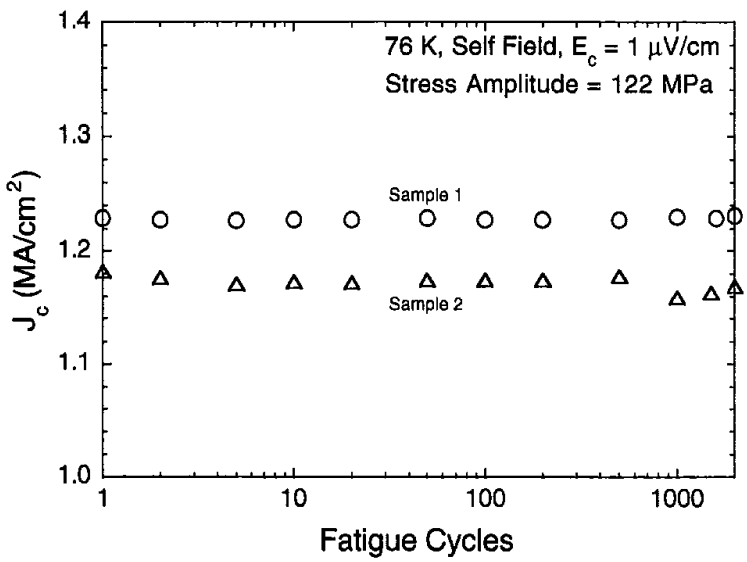

Fig. 4. Effect of cyclic loading on IBAD tapes (samples 1 and 2 correspond to Figs. $2 \mathrm{a}$ and $2 \mathrm{~b}$, respectively)

showed a total of $7 \% J_{c}$ degradation on initial loading in the incremental load-unload mode) the effect of an additional 2000 constant load cycles resulted in only $\sim 2 \%$ further degradation in $J_{c}$. Again, this represents high fatigue tolerance for these Ni-alloy-substrate IBAD conductors.

\section{MICROSTRUCTURAL CHARACTERIZATION}

After all mechanical testing had been performed (both static initial loading and fatigue tests), the samples were examined using magneto-optical imaging (MOI) [17] and scanning electron microscopy (SEM). Fig. 5 shows the MOI results. A comparison of Samples 1 and 2 shows no remarkable differences, even though Sample 2 degraded by a total of $9 \%$ ( $7 \%$ on initial loading plus $2 \%$ from fatigue), whereas Sample 1 had a total $J_{c}$ degradation of less than $1 \%$. Magnetic flux penetrated nearly uniformly and no obvious cracks were imaged at the MOI spatial resolution for these samples, about $10 \mu \mathrm{m}$. Also, there was no observable difference between the central pressed region of the samples and the ends, which received no transverse pressure.

After carefully etching away the $\mathrm{Ag}$ with a solution of $25 \% \mathrm{H}_{2} \mathrm{O}_{2}, 25 \% \mathrm{NH}_{4} \mathrm{OH}, 50 \% \mathrm{H}_{2} \mathrm{O}$, made fresh each time, the surface of the YBCO layer was examined using SEM. In Fig. 6 we see that a series of relatively thin longitudinal cracks $(\sim$ $0.05 \mu \mathrm{m}$ to $\sim 0.2 \mu \mathrm{m}$ in width) formed in the region near the tape edges of both samples. However, Sample 1 (with less than $1 \% J_{c}$ degradation) had a cracked region that extended only about $0.05 \mathrm{~mm}$ in from only one edge, whereas Sample 2 (which showed $9 \% J_{c}$ degradation after being subjected to the more severe load-unload mode) had a cracked region that occupied a much wider band, about $0.2 \mathrm{~mm}$ wide along one tape edge and about $0.1 \mathrm{~mm}$ wide along the other edge. The affected cross-sectional area of Sample 2 was measured to be about $\sim 9 \%$ of the tape width, corresponding closely to the observed $9 \% J_{c}$ degradation. The cracks were predominately in the longitudinal direction (along the direction of the transport current), with crosslinking. The center of the tape was free of any observable cracks. 


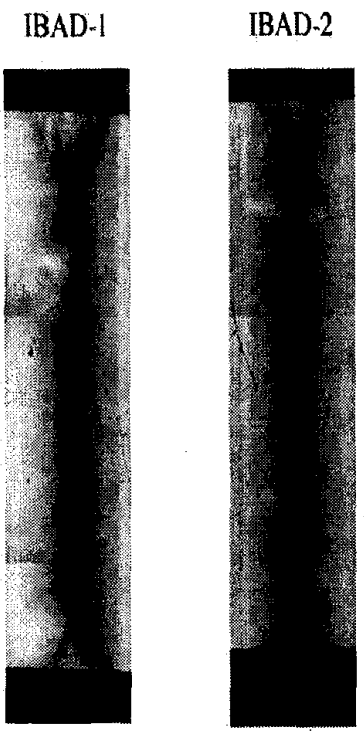

Fig. 5. Magneto-optical images of magnetic flux $(80 \mathrm{mT})$ penetration into IBAD tapes that had been subjected to static and cyclic transverse stress (images obtained after initially cooled to $15 \mathrm{~K}$ in zero field).

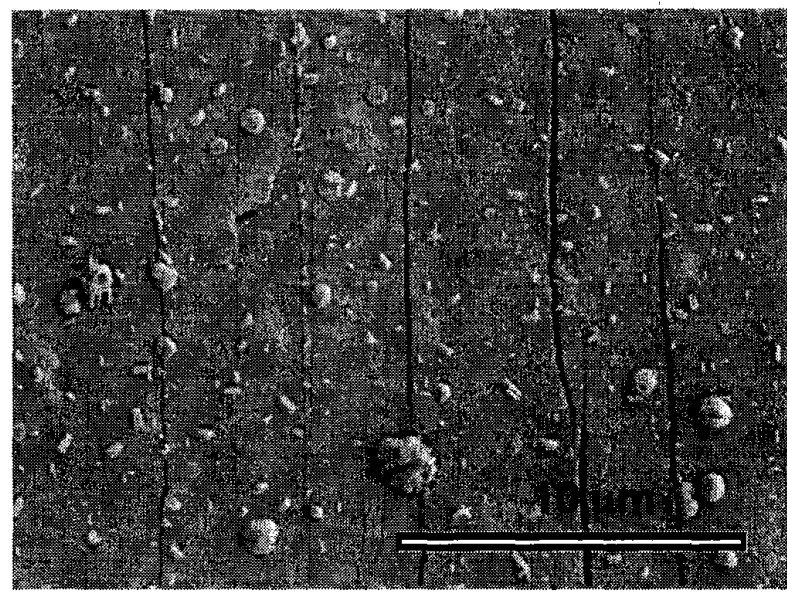

Fig. 6. Scanning electron micrograph of the YBCO surface of Sample 2 after static and cyclic transverse stress testing, showing the pattern of longitudinal cracks along the length of the tapes near the tape edges. For Sample 1, the affected region was only about $0.05 \mathrm{~mm}$ wide and occurred along only one edge of the tape. For Sample 2, the band of longitudinal cracks was much wider: $\sim 0.4 \mathrm{~mm}$ in width along one tape edge and $0.1 \mathrm{~mm}$ along the other edge.

\section{CONCLUSION}

These initial transverse stress tests of YBCO-coated IBAD tapes show that the conductors exhibit strong transversestress tolerance: less than $1 \%$ degradation in $J_{c}$ when monotonically pressed against a stainless-steel anvil at pressures up to $120 \mathrm{MPa}$, and about $7 \%$ degradation in $J_{c}$ when incrementally loaded and unloaded at pressures up to $120 \mathrm{MPa}$. Two thousand fatigue-loading cycles at $120 \mathrm{MPa}$ produced an additional degradation in $J_{c}$ of less than $2 \%$.

Micrographic examination of these samples after mechanical testing indicates that transverse in-plane strain near the tape edges may play a significant role in determining the $J_{c}$ degradation from transverse stress. This would suggest that in magnet applications, improvement in transverse stress tolerance may be achieved by providing transverse support to the conductors through the use of additional structural material co-fabricated or co-wound with the coated conductors, as well as from good lateral-side support in the design of a magnet winding pack.

\section{REFERENCES}

[1] Y. Ijima, N. Watanabe, O. Kohno, and Y. Ikeno, "In-plane aligned $\mathrm{YBa}_{2} \mathrm{Cu}_{3} \mathrm{O}_{7-\delta}$ thin films deposited on polycrystalline metallic substrates," Appl. Phys. Lett. Vol. 60, pp. 769-771 (1992).

[2] X. D. Wu, S. R. Foltyn, P. Arendt, J. Townsend, C. Adams, I. H. Campbell, P. Tiwari, Y. Coulter, and D. E. Peterson, "High current $\mathrm{YBa}_{2} \mathrm{Cu}_{3} \mathrm{O}_{7}$ - thick films on flexible $\mathrm{Ni}$ substrates with textured buffer layers," Appl Phys. Lett. Vol. 65, pp. 1961-1963 (1994).

[3] A. Goyal, D. P. Norton, J. D. Budai, M. Pranthaman, E. D. Specht, D. M. Kroeger, D. K. Christen, Q. He, B. Saffian, F. A. List, D. F. Lee, P. M. Martin, C. E. Klabunde, E. Hardtfield, and V. K. Sikka, Appl. Phys. Lett. Vol. 69, pp. 1975 - 1977 (1996).

[4] H. C. Feyhardt, J. Hoffmann, J. Wiesmann, J. Dzick, K. Heinemann, A. Isaeev, F. Garcia-Moreno, S. Sievers, and A. Usokin, $\mathrm{YBaCuO}$ thick films on planar and curved technical substrates," IEEE Trans Appl. Supercond. Vol. 7, pp. 1426-1431 (1997).

[5] S. K. Hasegawa, H. Mukai, M. Konishi, J. Fujikame, K. Ohmatsu, K. Hayashi, K. Sato, S. Honjo, H. Ishii, Y. Sato, and Y. Iwata, Adv. in Superconductivity X, Springer Verlay, Tokyo, p. 607 (1998).

[6] S. R. Foltyn, P. N. Arendt, P. C. Dowden, J. R. Groves, J. Y. Coulter, Q. X. Jia, X. F. Zhang, H. H. Kung, J. F. Bingert, E. J. Peterson, T. G. Holesinger, M. P. Maley, and D. E. Peterson, High- $T_{\mathrm{c}}$ coated conductors -- performance of meter-long YBCO/IBAD flexible tapes," IEEE Trans. Appl. Supercond. Vol. 9, pp. 1519-1522 (1999).

[7] S. L. Bray, J. W. Ekin, C. C. Clickner, and L. J. Masur, "Transverse compressive stress effects on the critical current of $\mathrm{Bi}-2223 / \mathrm{Ag}$ tapes reinforced with pure $\mathrm{Ag}$ and oxide-dispersion-strengthened $\mathrm{Ag}$, " $J$. Appl. Phys. Vol, 88, pp. 1178-1180 (2000).

[8] X. D. Wu, S. R. Foltyn, P. Arendt, W. R. Blumenthal, I. H. Campbell, J. D. Cotton, J. Y. Coulter, W. L. Hults, M. P. Maley, H. F. Safar, and J. L. Smith, "Properties of $\mathrm{YBa}_{2} \mathrm{Cu}_{3} \mathrm{O}_{7-8}$ thick films on flexible buffered metallic substrates," Appl. Phys. Lett. Vol. 67, pp. 2397-2399 (1995).

[9] DOE Annual 1998 Peer Review, presentation by ORNL, July (1998).

[10] C. L. H. Thieme, S. Fleshler, D. M. Buczek, M. Jowett, L. G. Fritzemeier, P. N. Arendt, S. R. Foltyn, J. Y. Coulter, and J. O. Willis, "Axial strain dependence at $77 \mathrm{~K}$ of the critical current of thick YBaCuO films on Ni-alloy substrates with IBAD buffer layers, "IEEE Trans. Appl. Supercond. Vol. 9, pp. 1494-1497 (1999).

[11] P. N. Arendt, S. R. Foltyn, J. R. Groves, R. F. DePaula, P. C. Dowden, J. M. Roper, and J. Y. Coulter, "YBCO/YSZ coated conductors on flexible Ni-alloy substrates", Appl. Supercond. Vol. 4, p 429 (1998).

[12] J. W. Ekin, "Superconductor Contacts," in the Handbook of Superconducting Materials, Inst. of Physics, England, to be published.

[13] P. E. Kirkpatrick, J. W. Ekin, and S. L. Bray, "A flexible high-current lead for use in high-magnetic-field cryogenic environments," Rev. Sci. Instr. Vol. 70, pp. 3338-3340 (1999).

[14] J. W. Ekin, "Current transfer in multifilamentary superconductors: Part I -- theory," J. Appl. Phys. Vol. 49, pp. 3406-3409 (1978).

[15] J. W. Ekin, "Irregularity in Nb-Ti filament area and electric field versus current characteristics," Cryogenics, Vol. 27, pp. 603-607 (1987).

[16] D. Dietderich and R. Scanlan, "Critical current variation as a function of transverse stress of Bi-2212 and $\mathrm{Nb}_{3} \mathrm{Sn}$ Rutherford cable", this conference.

[17] A. A. Polyanskii, X. Y. Cai, D. M. Feldman, D. C. Larbalestier, "Nanocrystalline and film magnetic oxides", ed. Ivan Nedkov and Marcell Ausloos, NATO Science Series No. 3, High Technology Vol. 72, Klewer Acad. Publisher pp. 353-370 (1989).

$\dagger$ Commercial products are mentioned for information only and do not imply recommendation or endorsement by NIST. 